\title{
ANALYSING THE RELEVANCE OF SERIOUS GAME ELEMENTS FOR EFFECTIVELY TEACHING INNOVATION PROCESSES
}

\author{
Ma, Yiming (1); Vallet, Flore (1,2); Cluzel, François (1); Yannou, Bernard (1) \\ 1: Laboratoire Genie Industriel, CentraleSupélec, Université Paris-Saclay, Gif-sur-Yvette, France; 2: \\ IRT SystemX, Gif-sur-Yvette, France
}

\begin{abstract}
Serious games (SGs) as a new educational format have gained interest among many scholars from diverse fields. SGs seem to be useful tools for teaching innovation processes (IP) as they guarantee intrinsic motivation and provide situated learning. So far, there is no guideline on designing IP games and lowering their development time while ensuring their effectiveness. To fill this gap, we should first analyse the existing IP games with evaluation methods and synthesise their commonalities. Numerous methods have been put forward in the literature to assess digital SGs; however, most of the SGs for IP are board games. That is why we explore in this paper the use of Serious Game Design Assessment (SGDA) framework to analyse IP board games. According to the case study on an open innovation board game, we suggest applying this method to examine the a priori relevance of game elements (components that make up a game system). Moreover, we make recommendations to complement the SGDA framework with Game and Learning Mechanics, and real-world information. This contribution should help designers transform traditional educational supports into serious board games for teaching IP.
\end{abstract}

Keywords: Design process, Innovation, Serious games, Game design elements, Open innovation

\section{Contact:}

Ma, Yiming

CENTRALESUPELEC

Industrial Engineering Research

France

yiming.ma@centralesupelec.fr 


\section{INTRODUCTION}

Innovation is the implementation of ideas aiming for the development of new products, procedures or practices (Rosa, Rodrigues and González, 2018). Innovation is one of the most critical concerns of each organisation and its role in the development and coordination of the market is inalienable (Tohidi and Jabbari, 2012). The Innovation Process (IP) is a structured process that allows a team to initiate innovation and facilitate the follow-up until success. There exist different types of IP, and they are part of the content knowledge of higher education. According to the results of a survey, half the American universities reviewed offered IP curricula to educate future innovators. However, most of these curricula appear as too much theoretical. Students lack opportunities to apply the knowledge practically (Glassman and Opengart, 2016).

Serious games (SGs) as a new educational format have gained interest in many scholars from diverse fields. The most common definition of a SG is "a digital game that does not have entertainment, enjoyment, or fun as their primary purpose" (Michael and Chen, 2006). However, some academic researchers extend the concept of SGs to all processes designed to learn and experiment, without necessarily using the support of video games (Mossoux et al., 2016). A serious game can be a board or a sports game as well. SGs seem to be useful tools for teaching innovation processes as they guarantee intrinsic motivation and provide situated learning (Agustin et al., 2015; Treviño-Guzmán and PomalesGarcía, 2014). So far, however, there is no guideline on designing SGs for IP. This guideline can reduce the time consuming for the game developing process while ensuring the effectiveness of the final product. To fill this gap, we should first analyse existing SGs for IP with evaluation methods. Through summarising the common characteristics of these games, we could establish the general design principles of an efficient SG for IP.

Evaluation methods are required to assess the effectiveness of SGs concerning their designated purpose. Emmerich and Bockholt (2016) state the advantages of a structured evaluation of SGs. For game developers, it advances the dissemination of SGs and improves future designs. For game researchers, the assessment of SGs not only helps them understand the impact of SGs on players but also develops guidelines for designing effective SGs. The intermediaries, those who have to support the use of SGs in their field of work, can get justification that SGs are useful tools. Moreover, for users, SGs evaluation can provide them with a better play and learning experience since it improves the designs of SGs. Numerous methods have been put forward in the literature to assess serious digital games. However, according to our survey, most of the SGs for IPs are board games. Therefore, a research question to be answered is "how can Digital Serious Game evaluation methods be used to evaluate Serious IP Board Games?". This issue is the focus of our paper.

The remainder of this paper proceeds as follows: Chapter 2 discusses previous works on SGs assessment methods. Chapter 3 explains the research methodology that we used and describes our case study on an open innovation board game. Chapter 4 presents the results and proposes a Serious Board Game Design Assessment (SBGDA) method for IP based on the Serious Game Design Assessment (SGDA) framework (Mitgutsch and Alvarado, 2012). Chapter 5 summarises and concludes the paper.

\section{SERIOUS GAMES ASSESSMENT METHODS}

A theoretical background grounded in SGs assessment methods is developed in this chapter. In general, we can classify all existing assessment methods from two perspectives (Emmerich and Bockholt, 2016): the time point of assessment (when to assess), and the content of assessment (what to assess).

\subsection{When to evaluate}

SGs have development life cycles as other products. The assessment methods applied are distinct depending on the stage of the SGs development life cycle. There is usually a difference between formative and summative assessments. Formative assessment is carried out during the development stage. This kind of evaluation is conducive to the further development of the SG. Summative assessment takes place after the development stage. It emphasises on the quality of the final product and the way to apply the product better. In literature, there are several methods which concern with the time point of assessment. For example, the famous Analysis Design Development Implementation Evaluation (ADDIE) framework (Molenda, 2003) covers both formative and summative evaluation. This framework emphasises that SGs 
development is not a sequential process; each development stage needs several iterations. The quality of the game is gradually improved thanks to these repetitions. Another popular summative assessment method is "pre-test/training/post-test." It serves to evaluate the quality of SGs by comparing the player's performance in a particular aspect before and after using the game.

\subsection{What to evaluate}

Many methods focus on the content of the assessment. Wouters et al. (2013) provide a meta-analysis method to evaluate the cognitive and motivational effects of SGs. More specifically, this method investigates whether SGs are more effective in terms of learning and more motivating than conventional instruction methods. Through testing the short-term and long-term retention of knowledge, we can assess the cognitive effects of a SG. Some researchers recommend using physiological or behavioural measures such as eye tracking and skin conductance to measure the motivation of players during gameplay objectively (Alkan and Cagiltay, 2007). After gameplay, the survey or questionnaire is used to measure subjective motivation. We present another example in section 2.3: the SGDA framework. It is one of the few methods that a priori analyse the game system itself. If this framework can be used to analyse IP board games, then we could deliver a rational decomposition of the design elements of them. By synthesising the typical characteristics of the same elements of different games, we will be able to establish the design principles of IP board games.

\subsection{Evaluation of the game system: SGDA framework}

The SGDA framework emphasises the cohesiveness and coherence between different SGs design elements. It is a primary game assessment which is useful for game designers but of course not sufficient as a SG must also be assessed during an actual game.

The SGDA framework starts with determining the game purpose and then analysing the relevance between other elements and game purpose. Besides the game purpose (a), the SGDA framework identifies six critical components of the formal conceptual design of the game system: (b) content \& information, (c) mechanics, (d) fiction \& narrative, (e) aesthetics \& graphics and (f) framing (Table 1).

Table 1. The SGDA framework (Mitgutsch and Alvarado, 2012)

\begin{tabular}{|c|l|}
\hline Game design elements & \multicolumn{1}{c|}{ Explanation \& Assessment criteria } \\
\hline Game purpose & The intention of a designer to design the game. \\
\hline Content \& Information & $\begin{array}{l}\text { The information or data offered and used in the game. All of the given } \\
\text { information should be valid, easily approachable and fact-based. }\end{array}$ \\
\hline Mechanics & $\begin{array}{l}\text { The methods invoked by agents for interacting with the game world, } \\
\text { general rules, in-game challenge, learning curve, and reward system. }\end{array}$ \\
\hline Fiction \& narrative & The created fictional space, relationship between story and game purpose. \\
\hline Aesthetics \& Graphics & The audiovisual language used in the game and its impact on the player. \\
\hline Framing & $\begin{array}{l}\text { The framing of other elements in terms of the target group, their play } \\
\text { literacy and the broader topic of the game. }\end{array}$ \\
\hline
\end{tabular}

\subsection{Summary}

In this chapter, we have provided a literature review of the existing SG evaluation methods. Among them, one method named SGDA caused our great attention since it is a template tool that states the principles and components of an a priori satisfactory IP game design. These components must be intimately bound up with the game purpose. Only when all the game design elements reflect the design purpose well can the game achieve the desired effects. The SGDA framework, like other SG assessment methods, is primarily made for serious digital games. How it could be used for analysing IP board games is unknown. Answering this question will fill a gap in the literature, by using this method to analyse a specific IP board game.

\section{METHODOLOGY}

We separate this chapter into two parts: the first part illustrates our research procedure while the second part introduces the case for testing the SGDA framework. 


\subsection{Research method}

The starting point of our research was a literature review, which led us to identify the research question of this paper. The literature review covered three aspects: SGs assessment methods, innovation processes and the existing SGs for teaching IP. Taking advantage of this review, we collected two crucial pieces of information: 1) all the SGs assessment methods were put forward based on serious digital games and 2) most of the existing SGs for teaching IP are board games. Especially for the literature review of existing IP serious games, we first used the Design Society Database (www.designsociety.org). By searching the keyword "serious game," 83 papers were found. Among these papers, there were 19 papers about specific serious games. However, only two of them concern serious games for teaching innovation processes (Boks and McAloone, 2009; Becker and Wits, 2014). The remaining papers focus on different topics, for example, "project management," "user experience design," and "design communication." To find more IP serious games, we used the Google search engine to do the same search and then found another seven games. All the games identified are multiplayer board games except "innovation makers" which is a single-player digital game (Table 2).

Table 2. The Panel of serious games on innovation and product development

\begin{tabular}{|c|c|c|}
\hline Name of the game & Reference & Type of the game \\
\hline Business Innovation Game & (Van Oudenhove, 2017) & Multiplayer \& board game \\
\hline SBCE & (Kerga et al., 2012) & Multiplayer \& board game \\
\hline Crossroads & (Bogers and Sproedt, 2012) & Multiplayer \& board game \\
\hline Creanov & (Diaz, 2017) & Multiplayer \& board game \\
\hline Creativ' & (Gharbi, n.d.) & Multiplayer \& board game \\
\hline Innovation maker & (Innovation Makers, n.d) & Single player \& digital game \\
\hline CONSORTi $\varnothing$ & (Jeu IØ, 2016) & Multiplayer \& board game \\
\hline Eco-board game & (Boks and McAloone, 2009) & Multiplayer \& board game \\
\hline Product development process game & (Becker and Wits, 2014) & Multiplayer \& board game \\
\hline
\end{tabular}

A case-study approach was chosen to determine whether the SGDA framework is viable to analyse the IP games. Our approach followed three phases: design of the SG experiment, data collection, and qualitative data analysis. First of all, we selected CONSORTiØ as the object of assessment. There were two reasons for choosing CONSORTiØ: (i) its purpose is ambitious in terms of learning a variety of reasons and solutions for deploying open innovation in companies, (ii) it is a board game which supports multiple people playing at the same time. Then, we got in touch with the game developers so as (i) to well understand their teaching intentions with the game, (ii) to select the experimental site and the participants accordingly to their requirements, (iii) to get their feedback of our SGDA assessment. We asked the game designers to animate themselves the SG experiment that we observed.

We present the detailed introduction of the case in section 3.2. During the SG experiment, the collection of data was carried out by the observations of the authors. We observed and recorded, in real time, the actions of trainer and players while playing the game. These data described the experimental process and content which were vital to the decomposition of design elements in CONSORTiØ. The qualitative analysis was conducted based on the SGDA framework and results are outlined in chapter 4 .

\subsection{Description of the case}

\subsubsection{Introduction of CONSORTIO}

CONSORTiØ is part of the Meilleures pratiques d'affaires (i.e., best business practices acknowledged by) of the Ministry of Economy, Science and Innovation of Quebec (MESI). It is a collaborative board game for teaching open innovation strategies (Figure 1a). The game designers recommend that at least two groups play it together, with four to six members in each group. In the game, players of a group constitute a consortium, and each of them represents an organisation within the consortium. The goal of the consortium is to develop new products by generating maximum value. Each organisation also comes with a personal business background, a budget (represented by the virtual currency) and an individual challenge (Figure 2b). Players cannot ignore the goal of the consortium while completing personal challenges. At each turn of the game, the consortium must make a decision on the open 
innovation strategies (using virtual currency to "purchase" open innovation strategies, e.g., Figure 2a) to be put in place according to multiple factors (e.g., available budget, individual challenges, and innovation capacity of the consortium). The designers measure the performance of the consortium by the value it creates (i.e., the amount of virtual currency earned by the consortium). The group with the best performance will be the final winner.

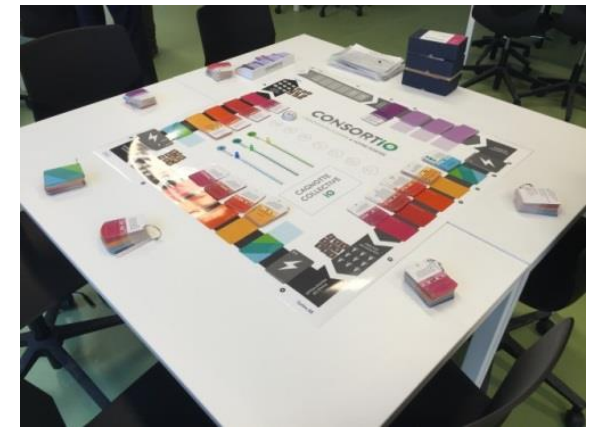

(a) Game board

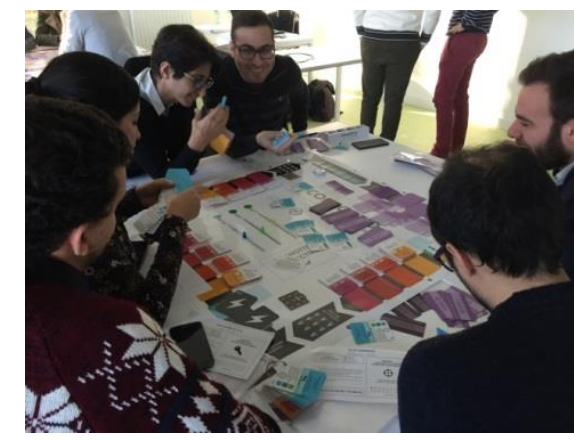

(b) Game session

Figure 1. The SG experiment of CONSORTi $\varnothing$

\subsubsection{SG experiment by using CONSORTIØ}

We conducted a serious game experiment in an engineering design course in October 2017 (Figure 1b). During the experiment, one designer of CONSORTi $\varnothing$ used this game to teach third-year master students and $\mathrm{PhD}$ students with open innovation strategies. There were 22 players participated, and they formed four groups (two of the groups had six players each, and the remaining two groups each had five players). The trainer divided the 6-hour experiment into two parts: theoretical course and game session. The theoretical course aimed to impart the basic knowledge of open innovation to players. For the game session, players started to learn specific open innovation strategies by playing CONSORTiØ. The game session contained three phases: the introduction of game rules, consortium formation, and the open innovation cycle. The open innovation cycle prescribed that the game has four turns: research, design, prototype, and deployment. Each of turns is corresponding to the different stages of development of one innovation project in reality.

\section{RESULTS}

\subsection{Analysis results of CONSORTIØ with the SGDA framework}

In section 4.1, the authors analyse the collected data according to the guidelines of the SGDA framework (Table 1) and present results of each game design elements in turn.

\subsubsection{Design purpose}

The topic of CONSORTiØ is open innovation. The purpose of the game contains three serious aspects and one fun aspect. Those three serious aspects are: make players 1) learn different strategies of open innovation, 2) understand how the benefits of open innovation can help businesses address their challenges, and 3) become aware of the importance of the preparation of the company and its partners (strategy and maturity) in the choice of open innovation strategies (Jeu IØ, 2016). The fun aspect is to provide a good experience for players while ensuring achieving the other serious aspects. The game also wants players to unfold imagination and answer the question about the future that "If you have to implement strategies of open innovation, what will they be?".

\subsubsection{Content \& Information}

The CONSORTiØ provides information about the definition and significance of open innovation and also examples of open innovation projects. These pieces of information are provided by the trainer using an hour of screen presentation. Game cards offer players information about their characters in the game and different open innovation strategies (Figure 2a; Figure2b). Besides, the players can access data on their progression in which they see how mature the consortium is and how much value they have generated 
thanks to the open innovation. Furthermore, the players can check the budget status of their organisation and track the decisions - cards selections - made by the consortium. After the game, each of them can get a card deck of the open innovation strategies.

All the given information of CONSORTiØ is valid and directly related to open innovation which meets the requirements of the SGDA framework. However, we found that there are two kinds of information: basic information as well as key information. Basic information is the information that game designers directly reference from other sources. The game designers extract key information from the real-world business environment. To use this information for game design, we should first organise and refine it. We hold the opinion that the analysis of information should not only focus on its correctness. Especially for the key information, its contribution to the achievement of design purpose and how it enhances the authenticity of the game requires further analysis. We identified three pieces of key information on CONSORTiØ. They are 1) the open innovation cycle model, 2) the intrinsic innovation capability model, and 3) the value created model. Here we take the second model as an example for discussion.

The intrinsic innovation capability model (labelled "CPR model") is used to evaluate the innovation capacity of each organisation as well as of the entire consortium. This model contains three indicators:

1) Culture: Have a culture of dynamic innovation and creativity encouraged in business, 2) Process: Have an appropriate organisational structure and adequate innovation processes, and 3) Resources: Know how to identify, integrate and make the best use of internal and external resources.

To understand how the CPR model serves the design goal, we analyse its usages in the game.

- One of the criteria to select the member of the consortium. At the beginning of the game, there are four mandatory roles and four optional roles, and players need to choose two more characters (if they have six people in the group) through balancing budget and CPR. This usage has three advantages:

- Make players aware of the importance of the culture, process, and resources when involved in an open innovation situation;

- Provide the criteria for assessing a company's ability to innovate in reality. The CPR model is useful to initial deployment of open innovation strategies in the company after the game;

- CPR is a simplified model of Lawson and Samson's (2001). The contents of the two models are the same. For example, "process" (CPR model) can cover a series of indicators "organisational intelligence, creativity and idea management, management of technology" (Lawson and Samson's model). The CPR model is more suitable for game design. It is much easier for players to understand the game rules thus to accelerate the process of the game and to provide players with smoother game experience.

- One of the preconditions for card selection. For example, Figure 2a shows one open innovation strategy card "focus group." To buy it, the indicators in the CPR model should be higher than 10, 20 and 15 in order. Considering this usage of CPR model, here are three advantages:

- The CPR model has a good mapping with the game rule that "choose good strategies of open innovation and apply them at the right moment." It avoids players to choose high maturity demanding strategies in the early stage of the game which is contrary to reality;

- The CPR model creates a link between game phases. At the beginning of each phase, players need first to choose capacity development cards to improve the CPR. Then they can purchase other open innovation tools which require higher maturity;

- The counters on the game board reflect the CPR model. These counters can offer immediate feedback to players and provide them with constant motivation.

- One source of value creation. In the generated value calculation stage of each phase, players need to follow one game rule: $1 \mathrm{CPR}=500 \mathrm{IO}$ (virtual currency). It means that the improvement of the consortium's ability to innovate will bring better economic benefits. Here are two advantages:

- The CPR model provides an intuitive way to express the value created. Players know their actions are effective. It makes players feel the ownership of the game and thus maintain excitement;

- It reflects a fact: one firm could get a considerable income by selling concepts and prototypes, but only innovation maturity is the fundamental guarantee for its continuous development.

\subsubsection{Mechanics}

For the mechanics, the SGDA framework focuses on the general rules of the game. However, it ignores the fact that game mechanics (GMs) make up the rules. So for a more in-depth analysis of mechanics, we adopted the method proposed by Arnab et al. (2015). Following this method, we detailed the usage and implementation of each GM and their related learning mechanics (LMs) that are contained in 
CONSORTiØ (Table 3). LMs are the dynamic operations of learning. The basis of this work is the "GMs space", and we introduce the space in section 4.2. CONSORTiØ uses LMs to ensure imparting the knowledge around open innovation. Simultaneously, it also uses a variety of GMs to enable players to enjoy fun during the learning process. Here we present part of results that related to the consortium formation phase. It is because of the use of these mechanics that players can quickly immerse themselves in the game world. Then learn and use open innovation strategies while completing the in-game challenges.

Table 3. Analysis results of mechanics (Arnab et al., 2015)

\begin{tabular}{|c|c|l|l|}
\hline Learning mechanics & Game mechanics & Implementation of GM & \multicolumn{1}{|c|}{ Usage of GM } \\
\hline \multirow{4}{*}{ Activity/ Project } & Role-play & $\begin{array}{l}8 \text { organisations to choose } \\
\text { from }\end{array}$ & $\begin{array}{l}\text { Immersion, interacting } \\
\text { with content }\end{array}$ \\
\cline { 2 - 4 } Action/Task & Selecting/Collecting & $\begin{array}{l}8 \text { tokens correspond to 8 } \\
\text { individual challenges }\end{array}$ & $\begin{array}{l}\text { Simplify and highlight the } \\
\text { in-game challenges }\end{array}$ \\
\cline { 2 - 4 } Reflect/Discuss & Collaboration & $\begin{array}{l}\text { Multiple organisations } \\
\text { within a consortium strive } \\
\text { for the same goal }\end{array}$ & $\begin{array}{l}\text { Enhance communication } \\
\text { among players to increase } \\
\text { the sense of integration }\end{array}$ \\
\cline { 2 - 5 } Problem-based solving & Time pressure & Time controlled by trainer & $\begin{array}{l}\text { Highlight urgency and } \\
\text { accelerate the game } \\
\text { process }\end{array}$ \\
\cline { 2 - 5 } & Strategy/Planning & $\begin{array}{l}\text { Communication among } \\
\text { players }\end{array}$ & $\begin{array}{l}\text { Immersion, to emphasise } \\
\text { that communication is vital } \\
\text { for team success }\end{array}$ \\
\hline
\end{tabular}

\subsubsection{Fiction \& Narrative}

The story in CONSORTiØ is about an open innovation project. Players are involved in the "SUPERGEL" food consortium. Its objective is to develop a line of frozen ready meals using the new super freezing technology developed by the C.R.A.M.P.: a fictive research centre and a member of the consortium. There are eight different characters to choose from; for example, FOODY.COM is an internationally recognised culinary blog (Figure 2b). The overall story of the game creates a context for players to learn and apply open innovation strategies. The background stories of each character can help players understand the organisation they represent and the challenges they face in the game.

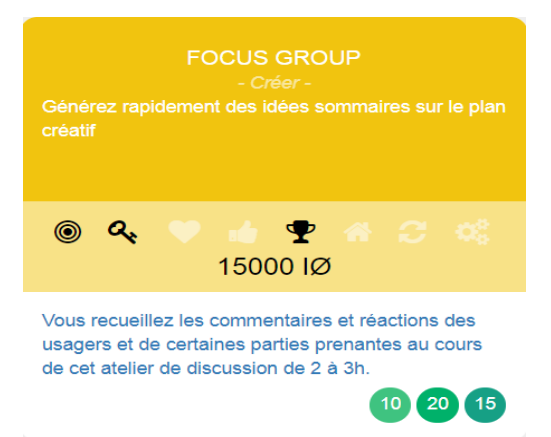

(a) Open innovation strategy card

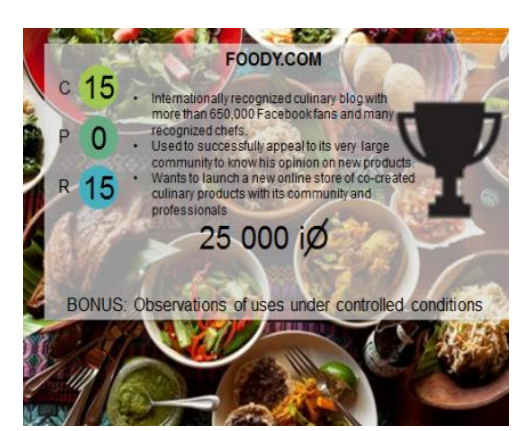

(b) Character card

Figure 2. Game cards

\subsubsection{Aesthetics \& Graphics}

Although CONSORTi $\varnothing$ cannot provide attracted 3D environment to players, proper design of game cards and game board also make players immersed. For the game card, CONSORTi $\varnothing$ uses simple and suitable icons to represent individual challenges. Players can easily remember these challenges. Clearly remembering the personal challenges helps players quickly identify open innovation strategies that are good for them. The game board of CONSORTi $\varnothing$ is designed based on the entire game process (open innovation cycle model). It helps players track game progress, and this kind of instant feedback allows players to maintain sufficient motivation and concentrate more on learning knowledge. 


\subsubsection{Framing}

A further additional aspect is the framing of the other five design elements in terms of the target group and their play literacy. CONSORTi $\varnothing$ targets a significant group of professionals whose work involves marketing, $\mathrm{R} \& \mathrm{D}$, and human resources. This game also aims at students from an engineering school or business school. These people have the motivation to learn open innovation. The trainers always combine the game with an academic course. They adjust the content and duration of the course based on the players' knowledge of open innovation. The play literacy needed to master the game is very basic because the trainer clearly explains the game rules before playing. The difficulty level increases from level to level, which is realised by the GM "time pressure." Players need to make decisions in less and less time. The learning challenges of CONSORTiØ also rest in the content. Only when players understand the open innovation strategies can they make the right decisions. Although the knowledge contained in the game mostly appears in the form of text (game cards), the successful use of GMs such as "role play" and "collaboration" provide players with a fascinating gaming experience. Players can download some teaching materials to review the knowledge learned in the game.

\subsection{Discussion: Serious Board Game Design Assessment (SBGDA) method for IP}

Based on the analysis results, the SGDA framework has been successfully applied to identify six key game design elements of CONSORTiØ and to analyse the relevance of these game elements. We suggest applying this method to analyse the other IP board games. There are two reasons: 1) IP board games are the purposebased systems and contain six key elements like other serious digital games, 2) The SGDA framework does not concern the most significant difference between a board game and a digital game: they use distinct media. Board games seem more suitable than digital games for teaching IP because board games can not only offer players opportunities of collaborative learning but also help them develop competencies (communication, creativity, and responsibility) for supporting innovation.

During the analysis, we found that the results obtained did not make us particularly satisfied. Above all, the SGDA framework does not allow us to perform a detailed analysis of the specific GMs that make up the rules, just staying at the general rule level. So we cannot identify the commonalities of existing IP games from the perspective of GMs. Furthermore, it ignores to analyse how the game content enhances the authenticity of the game. Gonçalves et al. (2010) insist that the authenticity is a critical concern in game-based learning since it not only keeps players immersing in the game but also ensures that the player can apply the knowledge acquired in the game to reality. To deepen the analysis of existing IP games, we put forward two suggestions for improving SGDA. We named the method as SBGDA method for IP (Figure 3). For the mechanics, our method emphasises the need to detail the usage and implementation of each GM and their related LMs. Only in this way, we can understand how games impart knowledge and create a gaming experience. For the information, we focus on analysing how key information enhances game authenticity. The key information concerns the business environment in reality as well as the related concepts of the innovation process that the game focuses. This improvement determines that the SBGDA method is specific to IP board games.

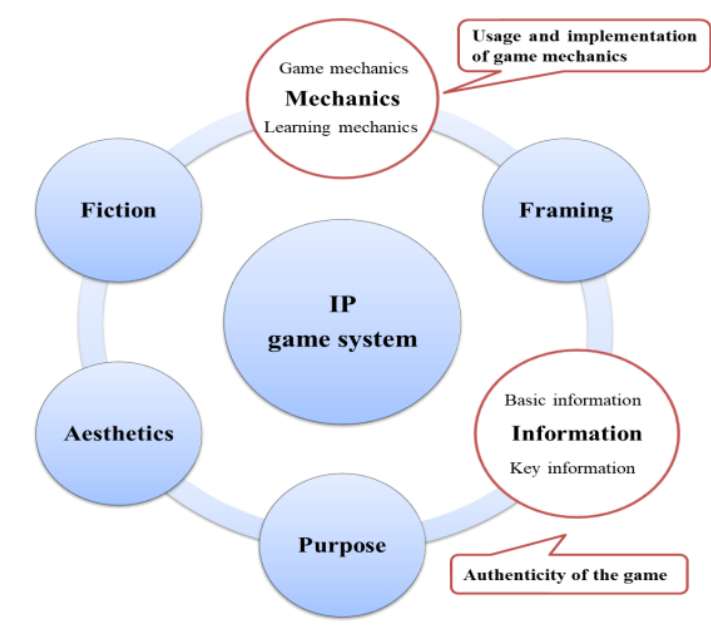

Figure 3. SBGDA method for IP based on the SGDA framework

Here we detail the improvement in terms of mechanics. To conduct the analysis of GMs and to guide the choice of GMs for future design, we created a GMs space. This space contains more than 70 different game 
mechanics (Table 4). We collected these GMs through three sources and then found definition and example for each of them.

Table 4. Game mechanics space (Schonfeld, 2010; Arnab et al., 2015; Marczewski, 2017)

\begin{tabular}{|c|c|c|c|c|c|c|c|c|}
\hline \multicolumn{9}{|c|}{ Game Mechanics } \\
\hline $\begin{array}{l}\text { Access } \\
\text { [B] }\end{array}$ & $\begin{array}{l}\text { Action points } \\
\text { [A] }\end{array}$ & $\begin{array}{l}\text { Anarchy } \\
{[B]}\end{array}$ & $\begin{array}{c}\text { Anonymity } \\
{[\mathrm{B}]}\end{array}$ & $\begin{array}{l}\text { Appointment } \\
{[\mathrm{A}, \mathrm{C}]}\end{array}$ & $\begin{array}{l}\text { Assessment } \\
{[\mathrm{A}]}\end{array}$ & $\begin{array}{c}\text { Badges } \\
{[\mathrm{A}, \mathrm{B}]}\end{array}$ & $\begin{array}{c}\text { Behavioral } \\
\text { Momentum } \\
{[\mathrm{A}]}\end{array}$ & $\begin{array}{l}\text { Boss Battles } \\
\text { [B] }\end{array}$ \\
\hline $\begin{array}{l}\text { Capture } \\
\text { [A] }\end{array}$ & $\begin{array}{c}\text { Care-taking } \\
{[\mathrm{B}]}\end{array}$ & $\begin{array}{c}\text { Cascading } \\
\text { information } \\
{[\mathrm{A}]}\end{array}$ & $\begin{array}{c}\text { Challenges } \\
{[\mathrm{A}, \mathrm{B}, \mathrm{C}]}\end{array}$ & $\begin{array}{l}\text { Collaboration } \\
\text { [A] }\end{array}$ & $\begin{array}{c}\text { Community } \\
\text { Discovery } \\
{[B]}\end{array}$ & $\begin{array}{c}\text { Competition } \\
{[\mathrm{A}, \mathrm{B}]}\end{array}$ & $\begin{array}{c}\text { Consequences } \\
\text { [B] }\end{array}$ & $\begin{array}{c}\text { Cooperation } \\
{[\mathrm{A}]}\end{array}$ \\
\hline $\begin{array}{l}\text { Customization } \\
\text { [B] }\end{array}$ & $\begin{array}{l}\text { Development tools } \\
\text { [B] }\end{array}$ & $\begin{array}{c}\text { Easter eggs } \\
\quad[\mathrm{B}]\end{array}$ & $\begin{array}{c}\text { Exploration } \\
{[\mathrm{A}, \mathrm{C}]}\end{array}$ & $\begin{array}{c}\text { Feedback } \\
{[A, B, C]}\end{array}$ & $\begin{array}{l}\text { Fixed reward } \\
\text { schedule } \\
{[\mathrm{B}, \mathrm{C}]}\end{array}$ & $\begin{array}{c}\text { Flow } \\
{[\mathrm{B}]}\end{array}$ & $\begin{array}{l}\text { Free lunch } \\
\quad[\mathrm{B}]\end{array}$ & $\begin{array}{l}\text { Game turns } \\
{[\mathrm{A}]}\end{array}$ \\
\hline $\begin{array}{l}\text { Sharing } \\
{[\mathrm{B}]}\end{array}$ & $\begin{array}{l}\text { Guilds } \\
\text { [B] }\end{array}$ & $\begin{array}{c}\text { Infinite } \\
\text { gameplay } \\
{[\mathrm{A}, \mathrm{C}]}\end{array}$ & $\begin{array}{l}\text { Investment } \\
{[\mathrm{B}]}\end{array}$ & $\begin{array}{l}\text { Leader board } \\
{[\mathrm{A}, \mathrm{B}, \mathrm{C}]}\end{array}$ & $\begin{array}{l}\text { Learning } \\
{[\mathrm{B}]}\end{array}$ & $\begin{array}{l}\text { Levels } \\
{[\mathrm{B}]}\end{array}$ & $\begin{array}{l}\text { Light touch } \\
{[\text { [B] }}\end{array}$ & $\begin{array}{l}\text { Lottery } \\
{[\mathrm{B}, \mathrm{C}]}\end{array}$ \\
\hline $\begin{array}{c}\text { Meta-game } \\
{[\mathrm{A}, \mathrm{C}]}\end{array}$ & $\begin{array}{l}\text { Movement } \\
{[\mathrm{A}]}\end{array}$ & $\begin{array}{l}\text { Modifiers } \\
{[\mathrm{C}]}\end{array}$ & $\begin{array}{c}\text { Mystery box } \\
{[\mathrm{B}]}\end{array}$ & $\begin{array}{c}\text { Ownership } \\
{[\mathrm{A}, \mathrm{B}, \mathrm{C}]}\end{array}$ & $\begin{array}{c}\text { Pareto Optimal } \\
{[\mathrm{A}]}\end{array}$ & $\begin{array}{c}\text { Pavlovian } \\
\text { interactions } \\
{[\mathrm{A}]}\end{array}$ & $\begin{array}{l}\text { Progress } \\
{[\mathrm{A}, \mathrm{B}, \mathrm{C}]}\end{array}$ & $\begin{array}{c}\text { Protégé effect } \\
\text { [A] }\end{array}$ \\
\hline $\begin{array}{l}\text { Purpose } \\
\text { [B] }\end{array}$ & $\begin{array}{l}\text { Q\&A } \\
{[\mathrm{A}]}\end{array}$ & $\begin{array}{l}\text { Quests } \\
\text { [B] }\end{array}$ & $\begin{array}{c}\text { Random reward } \\
{[\mathrm{B}]}\end{array}$ & $\begin{array}{l}\text { Rare content } \\
{[\mathrm{B}]}\end{array}$ & $\begin{array}{l}\text { Realism } \\
{[\mathrm{A}]}\end{array}$ & $\begin{array}{l}\text { Real-time vs } \\
\text { Delayed } \\
\text { [C] }\end{array}$ & $\begin{array}{c}\text { Resource } \\
\text { management } \\
{[\mathrm{A}]}\end{array}$ & $\begin{array}{l}\text { Role-play } \\
\quad[\mathrm{A}]\end{array}$ \\
\hline $\begin{array}{l}\text { Scarcity } \\
{[\mathrm{B}]}\end{array}$ & $\begin{array}{l}\text { Status } \\
{[\mathrm{A}, \mathrm{C}]}\end{array}$ & $\begin{array}{l}\text { Strategy } \\
{[A, B]}\end{array}$ & $\begin{array}{c}\text { Narrative } \\
{[\mathrm{A}]}\end{array}$ & $\begin{array}{c}\text { Social discovery } \\
{[\mathrm{B}]}\end{array}$ & $\begin{array}{c}\text { Social network } \\
{[\mathrm{B}]}\end{array}$ & $\begin{array}{c}\text { Social pressure } \\
{[\mathrm{B}]}\end{array}$ & $\begin{array}{l}\text { Social status } \\
{[\mathrm{B}]}\end{array}$ & $\begin{array}{l}\text { Theme } \\
{[B, C]}\end{array}$ \\
\hline $\begin{array}{c}\text { Grids } \\
{[\mathrm{A}]}\end{array}$ & $\begin{array}{l}\text { Time dependent } \\
\text { reward } \\
{[\mathrm{B}, \mathrm{C}]}\end{array}$ & $\begin{array}{c}\text { Time pressure } \\
{[\mathrm{A}, \mathrm{B}]}\end{array}$ & $\begin{array}{l}\text { Tokens } \\
{[\mathrm{A}, \mathrm{B}, \mathrm{C}]}\end{array}$ & $\begin{array}{l}\text { Tutorial } \\
{[\mathrm{A}, \mathrm{B}]}\end{array}$ & $\begin{array}{l}\text { Urgent optimism } \\
{[\mathrm{A}, \mathrm{C}]}\end{array}$ & $\begin{array}{l}\text { Virality } \\
{[\mathrm{A}]}\end{array}$ & $\begin{array}{c}\text { Virtual economy } \\
{[\mathrm{B}]}\end{array}$ & $\begin{array}{l}\text { Voting } \\
{[\mathrm{B}]}\end{array}$ \\
\hline Remark & {$[A]$ If the game me } & as been ide & m (Arnab & $15) ;[\mathrm{B}]$ If the & mechanic ha & entified fr & zzewski, 2017) & \\
\hline
\end{tabular}

When analysing IP board games with the SBGDA method, this space can help identify all the GMs that applied. Summarising the usage and implementation of these game mechanics conduce to the design of new IP games.

\section{SUMMARY AND OUTLOOK}

The research question of this study is: "How can Digital Serious Game evaluation methods be used to evaluate Serious IP Board Games?". We discovered this research gap through a literature review: most of the existing IP games are serious board games; however all the assessment methods are based on serious digital games. To fill this gap, we adopted a case-study approach that tests the use of SGDA framework to analyse the intention-based design of one IP board game - CONSORTiØ. We successfully applied the SGDA framework to deliver a rational decomposition of the design elements of CONSORTiØ. Therefore, we suggest using the method to analyse the IP board games. Here are two root causes for supporting the use of this method: 1) the six key design elements are also suitable to describe an (IP) board game, and 2) the SGDA framework does not involve the analysis of the media. Moreover, based on the SGDA framework, we proposed a SBGDA method for evaluating IP board games. This method enriches SGDA framework from two aspects: 1) mechanics, detail the usage and implementation of each game mechanic and their related learning mechanics 2) information, consider how key information, which extracted from the real-world business environment, enhances the authenticity of a game. These two improvements facilitate the analysis of how game elements reflect the design purpose. The SBGDA method cannot be directly used to measure the effectiveness of a game. Therefore, we still need to find other assessment methods that are suitable for IP games and concern learning outcomes. The other obvious limitation of this study is that the SBGDA method is put forward only based on one IP board game, whether it is also suitable for analysing other SGs of the same type still needs experiments. Also, analysing a more significant number of games will permit to synthesise the commonalities of these games to build a pattern language for designing IP board games.

\section{REFERENCES}

Alkan, S. and Cagiltay, K. (2007), "Studying computer game learning experience through eye tracking”. British Journal of Educational Technology, Vol. 38, No. 3, pp. 538-542.

Agustin, R. D., Purwarianti, A., Surendro, K. and Suwardi, I. S. (2015), "Instructional Design in Serious Game for Learning Based on Inquiry and Situated Learning Theory”. Advanced Science Letters, Vol. 21 No. 12, pp. 3667-3671. 
Arnab, S., Lim, T., Carvalho, M. B., Bellotti, F., de Freitas, S., Louchart, S., Suttie, N., Berta, R. and De Gloria, A. (2015), "Mapping learning and game mechanics for serious games analysis". British Journal of Educational Technology, Vol. 46, pp. 391-411.

Becker, J. J. and Wits, W. (2014), “An Experience-Based Approach to Teaching Product Design”. In DS 78: Proceedings of the 16th International Conference on Engineering and Product Design Education (E\&PDE14), Design Education and Human Technology Relations, University of Twente, The Netherlands, 04-05.09. 2014 (pp. 688-693).

Bogers, M. and Sproedt, H. (2012), "Playful collaboration (or not): using a game to grasp the social dynamics of open innovation in innovation and business education”. Journal of Teaching in International Business, Vol. 23 No. 2, pp. 75-97.

Boks, C. and McAloone, T. (2009), "The design of Eco Board Games as an umbrella approach to sustainable product design education”. Global Engineering Alliance for Research and Education (GEARE)-A Comprehensive Study \& Intern Abroad Program for Engineering Students.

Diaz, V. (2017), "Serious Game \& innovation : Trouver les innovations possibles d'un produit en jouant". Available at: https://www.grenoble-em.com/actualite-serious-game-innovation-trouver-les-innovationspossibles-dun-produit-en-jouant. (Accessed: 21 Nov, 2018)

Emmerich, K. and Bockholt, M. (2016), "Serious games evaluation: processes, models, and concepts". In Entertainment Computing and Serious Games (pp. 265-283). Springer, Cham.

Gharbi, N. (n.d.). “Creativ', Le jeu des idées neuves”. Available at: https://www.cipe.fr/jeux-etformations/creativ/\#1447438165937-ca8c92d6-d3adf177-6859. (Accessed: 21 Nov, 2018)

Glassman, A. M. and Opengart, R. (2016), “Teaching Innovation and Creativity: Turning Theory into Practice". Journal of International Business Education, Vol. 11, p. 113.

Gonçalves, C., Croset, M. C., Ney, M., Balacheff, N. and Bosson, J. L. (2010), “Authenticity in learning game: how it is designed and perceived". In European Conference on Technology Enhanced Learning (pp. 109122). Springer, Berlin, Heidelberg.

Innovation Makers. (n.d.), Available at: https://www.daesign.com/ innovation-makers. (Accessed: 21 Nov, 2018) Jeu IØ. (2016), Available at: http://jeuio.rhizome.group/about. (Accessed: 15 Mar, 2018)

Kerga, E., Akaberi, A., Tasich, M., Rossi, M. and Terzi, S. (2012), "Lean product development: Serious game and evaluation of the learning outcomes". In IFIP International Conference on Advances in Production Management Systems. Springer, Berlin, Heidelberg. (pp. 590-597)

Lawson, B. and D. Samson (2001), "Developing innovation capability in organisations: a dynamic capabilities approach”. International Journal of Innovation Management, Vol. 5 No. 3, pp. 377-400.

Marczewski, A. (2017), “52 GAMIFICATION MECHANICS AND ELEMENTS”. Available at: https://www.gamified.uk/user-types/gamification-mechanics-elements/. (Accessed: $30 \mathrm{Apr}, 2018$ )

Mitgutsch, K. and Alvarado, N. (2012), "Purposeful by design? : a serious game design assessment framework". In Proceedings of the International Conference on the foundations of digital games (pp. 121-128). ACM.

Molenda, M. (2003), "In search of the elusive ADDIE model". Performance improvement, Vol. 42 No. 5, pp. 34-36.

Mossoux, S., Delcamp, A., Poppe, S., Michellier, C., Canters, F. and Kervyn, M. (2016), "Hazagora: will you survive the next disaster?-A serious game to raise awareness about geohazards and disaster risk reduction”. Natural Hazards and Earth System Sciences, Vol. 16 No. 1, pp. 135-147.

Rosa, M., Rodrigues, L. and González, M. (2018), "Business games and creativity stimulus: the behavior of three different teams in the ideation process”. DS 91: Proceedings of NordDesign 2018, Linköping, Sweden, 14th-17th August 2018.

Schonfeld, E. (2010), “SCVNGR’s Secret Game Mechanics Playdeck”. Available at: https://techcrunch.com/2010/08/25/scvngr-game-mechanics/. (Accessed: 30 Apr, 2018)

Tohidi, H. and Jabbari, M. M. (2012). "The important of innovation and its crucial role in growth, survival and success of organisations". Procedia Technology, Vol. 1, pp. 535-538.

Treviño-Guzmán, N. and Pomales-García, C. (2014). "How Can a Serious Game Impact Student Motivation and Learning?”. In IIE Annual Conference. Proceedings (p. 514). Institute of Industrial and Systems Engineers.

Van Oudenhove, S. (2017). "The business innovation game”. Available at: http://www.businessvaluedesign.com/. (Accessed: 21 Nov, 2018)

Wouters, P., Van Nimwegen, C., Van Oostendorp, H. and Van Der Spek, E. D. (2013). "A meta-analysis of the cognitive and motivational effects of serious games”. Journal of educational psychology, Vol. 105 No. 2, p. 249.

\section{ACKNOWLEDGMENTS}

The authors wish to thank the designers of CONSORTiØ, in particular, Christophe Billebaud, and all the students who participated in the serious game experiment. In addition, we gratefully acknowledge the financial support from China Scholarship Council (CSC). 